\title{
EDITORIAL
}

\section{Special section on selected papers from the 2003 Chinese National Symposium on X-ray Diffraction}

Late last year, I had an opportunity to visit China and to attend the 8th Chinese National Symposium on X-ray Diffraction held from October 29 to November 1 at GuanXi University, Nanning, China. The symposium was jointly organized by the Committee on X-ray Diffraction of Chinese Physical Society, the Committee on Powder Diffraction of Chinese Crystallographic Society, and Guangxi University. I learned from the symposium organizers that powder diffraction is a very popular analytical technique in China. There are about 2,000 X-ray powder diffractometers, 500 XRD scientists and 2,500-3,000 technicians in China. Most Chinese universities offer experimental courses in X-ray diffraction. The National Symposium on X-ray Diffraction is held every 3 years, and the National Conference on Crystallography every 4 years. There are 15 ICDD members, and about 16 Chinese scientists receive Grants-in-Aid from ICDD.

The 2003 Chinese National Symposium on X-ray Diffraction had about 150 participants (50\% from universities, $32 \%$ government institutes, $10 \% \mathrm{X}$-ray equipment representatives, $5 \%$ industry, and $3 \%$ overseas guests). A significant number of the participants were female, and the ratio between female and male was 1:2. More than 60 technical pa- pers on theoretical research, experimental techniques, structural determinations, and XRD applications were presented at the Symposium. I found that the qualities of many papers presented at the 2003 Symposium were good and the results were quite interesting. In order for the readers of Powder Diffraction to learn more about X-ray diffraction works in China, I asked the symposium organizers to encourage their speakers to prepare and submit papers for possible publication in Powder Diffraction. I am delighted that we are able to publish seven Chinese papers in a special section of the December 2004 issue of Powder Diffraction. I hope that our readers will enjoy reading these papers and can learn more about X-ray diffraction activities conducted by our colleagues in China. Finally, I want to thank Professors X.-L. Chen, S.-F. Lin, Y.-Y. Qiao, and X.-K. Yao of China for selecting and reviewing these papers. Special thanks also to Professor L.-M. Zeng, Local Chairman of the Symposium, for being an excellent host for my visit to China.

Ting C. Huang Editor-in-Chief 